\title{
Behavioral Effects of Opioid Full and Partial Agonists During Chronic Buprenorphine Treatment
}

\author{
Sarah L. Withey, Roger D. Spealman, Jack Bergman, and Carol A. Paronis \\ Behavioral Biology Program, McLean Hospital/Harvard Medical School, Belmont, Massachusetts \\ Received April 12, 2019; accepted August 1, 2019
}

\begin{abstract}
Buprenorphine, a partial agonist at the $\mu$-opioid receptor, is commonly prescribed for the management of opioid addiction. Notwithstanding buprenorphine's clinical popularity, the relationship between its effectiveness in attenuating relapse-related behavior and its opioid efficacy is poorly understood. Furthermore, changes in the antinociceptive potency or effectiveness of opioid drugs that might occur during buprenorphine treatment have not been characterized. Here, we address these questions by assessing the ability of daily buprenorphine treatment to protect against the reinstatement of drug-seeking behavior by six opioids differing in efficacy (methadone, heroin, oxycodone, buprenorphine, butorphanol, nalbuphine) and, in separate experiments, by determining how such treatment may modify their antinociceptive effects. In one set of experiments, squirrel monkeys were trained to respond under concurrent schedules (choice) of food or intravenous oxycodone presentations. The priming strength of different opioids during sessions in which saline, rather than oxycodone, was available for intravenous self-administration was determined before and during chronic buprenorphine treatment $(0.1$ or $0.32 \mathrm{mg} / \mathrm{kg}$ per day). In other
\end{abstract}

subjects, antinociceptive effects of the different opioids were assessed using cumulative dosing procedures in a modified warm-water tail withdrawal procedure before and during buprenorphine treatment. Results show that, notwithstanding some tolerance, full agonists retain high efficacy in producing priming and antinociceptive effects. In contrast, both the priming strength and antinociceptive effectiveness of partial agonists were decreased. These results suggest that the utility of buprenorphine in the management of opioid addiction, and how it alters the analgesic effects of opioids, can vary depending on the efficacy of the abused or prescribed opioid.

\section{SIGNIFICANCE STATEMENT}

Our findings indicate that the pharmacological efficacy of abused opioids may predict the ability of buprenorphine to attenuate their relapse-related priming and analgesia-related antinociceptive effects. This information can help inform physicians as to the effectiveness and limitations of buprenorphine as a pharmacotherapy for opioid addiction.

\section{Introduction}

Buprenorphine, a $\mu$-opioid receptor partial agonist, is often used in the management of opioid addiction. Buprenorphine displays high binding affinity at both $\mu$ - and $\kappa$-opioid receptors (Romero et al., 1999; Huang et al., 2001; Negus et al., 2002) and a slow rate of dissociation from the $\mu$-opioid receptor (Rance, 1979) — a profile of action that results in prolonged clinical effects and limited indications of physical dependence or abuse liability. Furthermore, the relatively low ceiling on buprenorphine's $\mu$-agonist activity precludes the severity of respiratory depression and toxicity observed with opioids such as fentanyl or heroin (Walsh et al., 1995; Liguori et al., 1996; Nielsen and Taylor, 2005). As a partial agonist, buprenorphine also has been shown to antagonize in vitro (Romero et al., 1999) and in vivo (Walker et al., 1995; Kishioka et al., 2000; Paronis and Bergman, 2011) effects of higher-efficacy $\mu$-opioid agonists, such as morphine or heroin, and to attenuate the subjective effects of opioid agonists following acute or

This work was supported by the National Institutes of Health [Grant DA035857].

https://doi.org/10.1124/jpet.119.259010. daily administration (Bickel et al., 1988; Briscoe et al., 2000). Due to its favorable pharmacokinetic and pharmacodynamic profile and its ability to attenuate the reinforcing effects of self-administered opioids (Mello and Mendelson, 1980; Comer et al., 2001), buprenorphine is an attractive pharmacotherapy for opioid addiction and, depending on the patient cohort, is often the primary choice of opioid-replacement therapy (Nielsen et al., 2012). Existing data support the view that buprenorphine can serve as an effective means for reducing relapse liability among former opioid abusers. For example, Tkacz et al. (2012) concluded that patients maintained on buprenorphine were 10 times less likely to relapse as long as they remained compliant with their treatment regimen.

Notwithstanding the current prescription of buprenorphine for treating opioid addiction, factors that may influence its effectiveness in precluding relapse, e.g., the type of opioid exposure during buprenorphine treatment, have not been systematically explored in either human or nonhuman laboratory subjects. This is especially a concern with the increasing abuse of opioids that are higher in both potency and efficacy, e.g., fentanyl and its analogs, than other prescription drugs or illicit opioids, including oxycodone or heroin, that are also widely abused. Understandably, such studies are difficult 
to conduct in human subjects due to ethical constraints on exposing otherwise abstinent individuals to priming doses of opioids. It is perhaps more surprising that such laboratory studies have not been conducted in nonhuman subjects. For example, reinstatement procedures, in which the dependent variable is the extent to which priming doses of drugs or other drug-related stimuli can provoke self-administration behavior, i.e., "drug-seeking," have been widely used to study factors that may contribute to or dampen relapse. In such procedures, a drug's ability to reinstate self-administration behavior can serve as a measure of its priming strength. Assessing changes in an opioid's priming strength during chronic buprenorphine should provide useful information regarding its ability to promote relapse during treatment.

Another understudied aspect of buprenorphine's pharmacology is the effect of chronic treatment on opioid antinociception. As discussed earlier with regard to relapse, the ability of opioids to retain antinociceptive capabilities during chronic treatment may depend on the level of opioid efficacy. Thus, reduced sensitivity to the analgesic effects of opioids occurs during chronic treatment with the higher-efficacy opioid agonist methadone due to cross-tolerance (Silverman, 2009). Buprenorphine may produce similar cross-tolerance or, as a $\mu$-partial agonist, it may functionally antagonize the antinociceptive effects of opioid agonists; in either case, higher doses of such opioids would be required to achieve pain relief, and it is possible that lower-efficacy agonists may no longer retain analgesic capability. Although these possibilities are of clear clinical concern, they have not been adequately evaluated in either clinical or preclinical studies of antinociception during chronic buprenorphine treatment.

The present studies were conducted in squirrel monkeys to address both sets of concerns discussed earlier by determining how chronically administered buprenorphine modulated the ability of different opioids to reinstate intravenous selfadministration behavior in a self-administration choice procedure and, in separate experiments, to produce opioid antinociception in a warm-water tail withdrawal assay. Under self-administration choice conditions, responding on two levers was maintained under concurrent schedules of reinforcement; intravenous drug injection or food delivery followed responding on one or the other of the two levers, respectively. Thus, the relative strength of different reinforcing or priming events could be quantified in terms of the distribution of behavior across the two levers. This approach allows self-administration data to be analyzed in a manner that is relatively independent of the response rate-disrupting effects of self-administered drugs (Paronis et al., 2002; Gasior et al., 2004; Bergman and Paronis, 2006). In antinociception studies, a modified warm-water tail withdrawal assay (Dykstra and Woods, 1986) was used to concurrently measure the effects of opioids on tail withdrawal latency and operant performance, permitting an evaluation of disruptive effects of opioids (sedation or stupor) that may complicate the interpretation of increases in tail withdrawal latency. Previous studies have shown that the potency ratio for these endpoints varies across opioids differing in efficacy, providing a firm basis for the present studies (Withey et al., 2018).

\section{Materials and Methods}

\section{Subjects}

Eight adult male squirrel monkeys (Saimiri sciureus) were housed in a climate-controlled vivarium with a 12-hour light/dark cycle
(7 AM to $7 \mathrm{PM}$ ) in the McLean Hospital Animal Care Facility licensed by the US Department of Agriculture and compliant with guidelines provided by the Committee on Care and Use of Laboratory Animals of the Institute of Laboratory Animals Resources, Commission on Life Sciences(National Research Council, 2011). Experiment 1 was conducted in one group of four subjects, and experiment 2 was conducted in a separate group of four subjects. Subjects were fed a high-protein primate chow (Purina Monkey Chow, St. Louis, MO) supplemented with fruit and multivitamins and, except during testing, had unrestricted access to water in the home cage. Food intake was not restricted in the present studies; after daily weighing, diets were adjusted as needed to maintain stable body weights. Experimental sessions were conducted 5 days/week (Monday to Friday between $8 \mathrm{AM}$ and $6 \mathrm{PM}$ ) under protocols approved by the Institutional Animal Care and Use Committee at Mclean Hospital.

All subjects had previously participated in studies involving acute injection of drugs from different pharmacological classes but had not received any drugs or participated in any studies for at least 1 month prior to the present research.

\section{Chronic Dosing}

The daily doses of buprenorphine in the current study were 0.1 and $0.32 \mathrm{mg} / \mathrm{kg}$ per day and, based on body weight, were selected to reflect the maintenance doses of buprenorphine used to minimize withdrawal symptoms in studies of opioid drugs (2-24 mg/day) ((Jones et al., 2015)(Rosenthal et al., 2016)). Subjects were injected with intramuscular buprenorphine daily, approximately 3 hours after the selfadministration session. This ensured the direct effects of the self-administered drug had subsided prior to treatment. Given the long duration of action of buprenorphine, it is likely that the data collected in the current studies would yield similar results to studies investigating prolonged-release and depot injection formulations of buprenorphine (Walsh et al., 2017). In reinstatement studies (experiment 1), daily treatment with $0.1 \mathrm{mg} / \mathrm{kg}$ of buprenorphine continued for 5 months, during which the priming effects of opioid full and partial agonists were studied in all subjects. Subsequently, the dose of buprenorphine was increased from 0.1 to $0.32 \mathrm{mg} / \mathrm{kg}$, and the priming strength of opioid full agonists was re-evaluated. In antinociception and behavioral disruption studies (experiment 2), daily treatment with $0.1 \mathrm{mg} / \mathrm{kg}$ of buprenorphine continued for 3 months, and subsequently, the dose of buprenorphine was increased to $0.32 \mathrm{mg} / \mathrm{kg}$. The antinociceptive and behaviorally disruptive effects of opioid full and partial agonists were studied during treatment with both 0.1 and $0.32 \mathrm{mg} / \mathrm{kg}$ of buprenorphine.

\section{Experiment 1-Priming-Induced Reinstatement of Drug-Seeking Behavior}

Apparatus. During self-administration experiments, subjects sat in a Plexiglas chair in a ventilated, sound-attenuating enclosure. Subjects faced a panel containing two response levers, colored stimulus lights, and a custom-designed Plexiglas receptacle $(5 \times 3.5 \times 1.27 \mathrm{~cm})$ mounted in the center. Each press of the lever with a force greater than $0.2 \mathrm{~N}$ produced an audible click and was recorded as a response. Two injection pumps (PHM-100-10; Med Associates, St. Albans, VT) outside the enclosure were used to deliver intravenous drug injections $(0.1 \mathrm{ml} /$ injection $)$ via an indwelling catheter and $20 \%$ sweetened condensed milk solution $(0.15 \mathrm{ml} /$ delivery) into the Plexiglas receptacle. All experimental events and data collection were controlled by a Med Associates MED-PC software package (Med Associates, East Fairfield, VT).

Procedure.

Training. Subjects first were trained to respond on one lever under a 30-response fixed-ratio (FR30) schedule of milk delivery. During initial training sessions, responses on the other lever were recorded but had no programmed consequences. Completion of the FR30 on the active lever turned off the stimulus lights, delivered the reinforcer, 
and initiated a time-out (TO) period of 45 seconds, during which all stimulus lights were off and responding on either lever had no scheduled consequences. Following initial training, the active lever was switched and delivery of the reinforcer (milk) required completion of FR30 on the opposite lever, leaving the initial lever inactive. This reversal training ensured subjects would readily reallocate responding based on the reinforcer available. Following this phase of training, each subject was assigned a drug- and milk-associated lever, and lever assignments were counterbalanced across subjects. Indwelling intravenous catheters were then implanted as described later and, ultimately, intravenous injections of oxycodone $(0.1 \mathrm{ml} /$ injection $)$ replaced milk deliveries on the drug-associated lever, under the FR30 schedule of reinforcement.

Oxycodone self-administration. Each subject was prepared with an intravenous catheter for drug delivery using well established surgical procedures (Goldberg, 1973). In brief, the subject was anesthetized using isoflurane, and one end of a hydrophilically coated polyurethane catheter $(0.381 \mathrm{~mm}$ inside diameter, $0.762 \mathrm{~mm}$ outside diameter) was inserted and secured into a femoral or jugular vein under aseptic conditions. Catheters were passed subcutaneously and exited the subject's back. When not in use, the externalized portions of the catheters were closed with obturators and stored in an inside pocket of a nylon jacket worn by the subject at all times.

Initial sessions were 60 minutes, and following development of robust responding for intravenous injections of oxycodone, session length was increased to 90 minutes. Oxycodone dose-response functions [0.0032-0.1 mg/kg per injection (inj)] were determined in each subject. Doses were studied in an irregular order for a minimum of 2 days and until session intake across two consecutive sessions was stable (within $20 \%$ with no upward or downward trends). The unit dose that resulted in the maximum number of intravenous injections, alternating with intravenous saline, was used during self-administration sessions for the remainder of the study. Baseline performance for all monkeys was characterized by nearly exclusive responding on the food lever when saline was available for self-administration and nearly exclusive responding on the injection lever when the selected dose of oxycodone was available for self-administration. The availability of saline or oxycodone for self-administration changed under a doublealternation schedule (i.e., saline-saline-oxycodone-oxycodone-salinesaline). Once stable patterns of responding developed, reinstatement studies commenced.

Reinstatement test sessions. The priming strength of opioid full agonists $(0.01-0.56 \mathrm{mg} / \mathrm{kg}$ heroin, $0.1-1.0 \mathrm{mg} / \mathrm{kg}$ methadone, and $0.1-1.0 \mathrm{mg} / \mathrm{kg}$ oxycodone) and opioid partial agonists $(0.01-3.2 \mathrm{mg} / \mathrm{kg}$ nalbuphine, $0.0032-1.8 \mathrm{mg} / \mathrm{kg}$ butorphanol, and $0.001-0.032 \mathrm{mg} / \mathrm{kg}$ buprenorphine) was determined in all subjects. On test days (usually the second daily saline session), intravenous saline injections were available for self-administration, and a single intramuscular injection (i.e., prime) of an opioid full or partial agonist was given 10 minutes prior to the beginning of the session. The intramuscular route of administration was chosen to distinguish between the noncontingent priming injection and the response-contingent intravenous drug or saline injection. Drug-seeking behavior was calculated as the percentage of responding on the injection lever when only saline was available for intravenous self-administration. Test sessions to determine the effects of priming drugs lasted for 30 minutes. For each subject, drugprime test sessions were conducted no more frequently than twice per week and only following a saline self-administration session in which the subject's behavior was allocated predominantly to the food lever.

Data Analysis. Data were obtained for three dependent variables in each session: distribution of responding on the injection lever (\% ILR), number of self-administered injections and milk reinforcers, and total drug intake. The \% ILR represents the percentage of responses allocated to the injection lever over the duration of the session (90 minutes for oxycodone self-administration or 30 minutes for priming-induced reinstatement sessions). The numbers of self-administered injections and milk deliveries were counted by MED-PC (Med Associates). Group means \pm S.E.M. were calculated by averaging the means of four monkeys and were analyzed using ANOVA for repeated measures (GraphPad Software, San Diego, CA).

\section{Experiment 2-Opioid-Induced Antinociception and Behavioral Disruption}

Apparatus. During experimental sessions, monkeys were seated in customized Plexiglas chairs that allowed their tails to hang freely behind the chair. While seated, subjects faced the chair's front panel, which was outfitted with two pairs of colored stimulus lights at eye level and a response lever below each set of lights. A receptacle was situated between the response levers; small volumes of sweetened condensed milk could be delivered into the receptacle via polyethylene tubing connected to a pump outside the chamber. Responding on the left lever was reinforced under the schedule described in the Procedure section below ("active" lever), whereas responding on the right lever had no scheduled consequences ("inactive" lever). During the session, each press of the active lever with a force of at least $0.2 \mathrm{~N}$ (lever press) produced an audible click of a relay and was recorded as a response.

Procedure. Methods for the warm-water tail withdrawal procedure have been described previously (Withey et al., 2018). In brief, subjects were trained to respond under a fixed-ratio 10-response (FR10) schedule of food reinforcement $(0.15 \mathrm{ml}$ of $30 \%$ sweetened condensed milk in water). Under this schedule, completion of 10 responses on the active lever during the illumination of red stimulus lights turned off the lights, triggered milk delivery, and initiated a TO period of 30 seconds, during which all stimulus lights remained off and responding had no scheduled consequences. A 20 -second limited hold was imposed on the FR10 schedule requirement; that is, the elapse of 20 seconds before the completion of 10 responses turned off stimulus lights and initiated the 30 -second TO but did not trigger milk delivery. Tail withdrawal latencies were measured during each of the 30 -second TO periods. Experimental sessions comprised four or five sequential cycles to permit cumulative drug dosing during test sessions. During test sessions, each cycle began with a 10-minute TO, during which no lights were on and responding had no programmed consequences. A cumulative dose of drug or injection of vehicle was administered shortly after the onset of the 10-minute TO. After the 10-minute TO elapsed, stimulus lights were illuminated, initiating a 5-minute response component during which the FR10 schedule of food reinforcement was in effect. Upon the passage of the 5-minute response component, stimulus lights were turned off, initiating the next cycle of the session.

To study antinociceptive effects of drugs, the latency to withdraw the tail from $55^{\circ} \mathrm{C}$ water was measured in each subject after treatment with vehicle or different doses of test drugs. In brief, the subject's tail was immersed in water $\left(35\right.$ or $\left.55^{\circ} \mathrm{C}\right)$ during each of the 30-second TOs of the 5-minute component. The response to $55^{\circ} \mathrm{C}$ water was tested only once in each component, and the cycle in which it was tested varied irregularly across consecutive components of the session and, for each drug, across monkeys; all other tail immersions during each component were at $35^{\circ} \mathrm{C}$. Tail immersion in $55^{\circ} \mathrm{C}$ water occurred only when control values were obtained in the immediately preceding immersion in $35^{\circ} \mathrm{C}$. This latter provision ensured that the subsequent withdrawal of the tail from $55^{\circ} \mathrm{C}$ water reflected a nociceptive response. The limited hold contingency ensured that the number of determinations per component ranged from 6 to 10, depending on the number of reinforcement deliveries during the component. Each drug was studied by administering cumulative intramuscular doses shortly after the onset of the 10-minute TO periods. Data from sessions in which sequential injections of saline vehicle were administered intramuscularly across components provided baseline control values. Training and test sessions typically comprised four or five cycles but were discontinued before completion of the fourth cycle if response rates during the preceding response component were below 0.2 responses per second. 
Data Analysis. Overall rates of responding (responses per second) were calculated for each cycle by dividing the number of lever presses emitted in the presence of stimulus lights by the time during which the stimulus lights were illuminated. Individual mean control values were calculated by averaging response rates obtained during the four components of the control sessions in which sequential injections of saline were administered. Statistical analysis was conducted with Prism version 5.02 (GraphPad Software) with doses expressed as logtransformed values. $\mathrm{ED}_{50}$ values were calculated by linear interpolation for increases in tail withdrawal latency and decreases in response rate after agonist administration. The $\mathrm{ED}_{50}$ for decreases in response rate for each drug was divided by the $\mathrm{ED}_{50}$ for the drug's effect on tail withdrawal latency to provide an index of the behavioral selectivity of its antinociceptive effects versus its behaviorally disruptive effects. Group $\mathrm{ED}_{50}$ ratios for each behavioral measure were calculated from the average of individual $\mathrm{ED}_{50}$ values.

\section{Drugs}

Oxycodone hydrochloride and nalbuphine hydrochloride were purchased from Sigma/RBI (Natick, MA). Heroin hydrochloride and buprenorphine hydrochloride were obtained from the National Institute on Drug Abuse (Rockville, MD). Methadone hydrochloride and butorphanol tartrate were obtained from Eli Lilly (Indianapolis, IN) and Bristol Laboratories (Evansville, IN), respectively. Drugs were dissolved and diluted to desired concentrations in sterile $0.9 \%$ saline and filter-sterilized using a $0.22-\mu \mathrm{m}$ Millipore filter (Millipore Corporation, Billerica, MA). Drug doses are expressed in terms of their freebase weights. Drugs administered by intramuscular injection were injected into the calf or thigh muscle in volumes of $0.3 \mathrm{ml} / \mathrm{kg}$ of body weight or less. In both self-administration and antinociception experiments, the order of drugs tested varied among subjects. In line with dosing procedures used by Withey et al. (2018), a 10-minute pretreatment time was used for all intramuscular injections.

\section{Results}

Oxycodone Self-Administration Control Performance. Oxycodone self-administration was successfully established in the group of four monkeys, as \% ILR for oxycodone injections increased in a dose-dependent manner in all subjects (Fig. 1A, filled symbols). \% ILR was $100 \%$ at unit doses of oxycodone equal to or greater than $0.01 \mathrm{mg} / \mathrm{kg}$ per inj (i.e., all responses were allocated to the injection lever). The unit dose of $0.01 \mathrm{mg} / \mathrm{kg}$ per inj was also the dose that occasioned the greatest number of self-administered injections of oxycodone (Fig. 1B, filled symbols), resulting in, on average, $35.3 \pm 6.3$ injections per session. When either lower

\section{Pre-chronic $\square$ Chronic buprenorphine $0.32 \mathrm{mg} / \mathrm{kg}$}

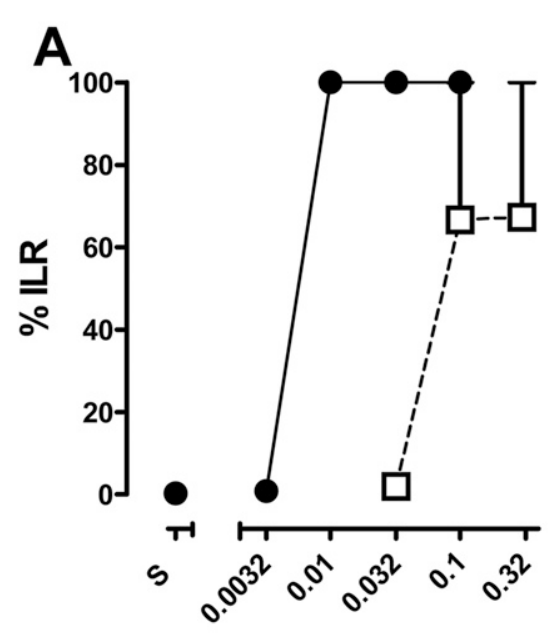

C

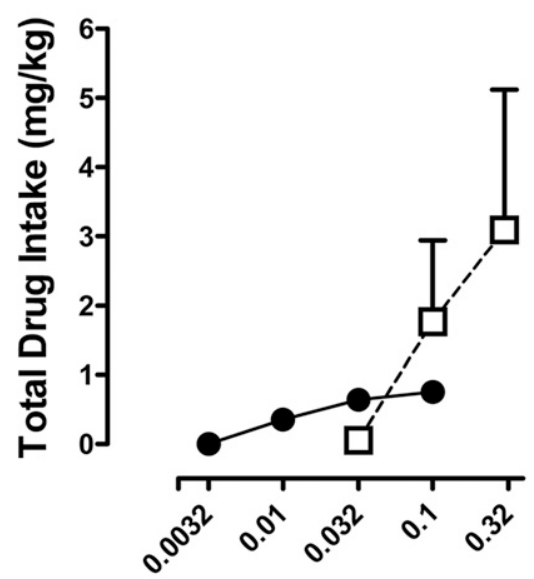

B

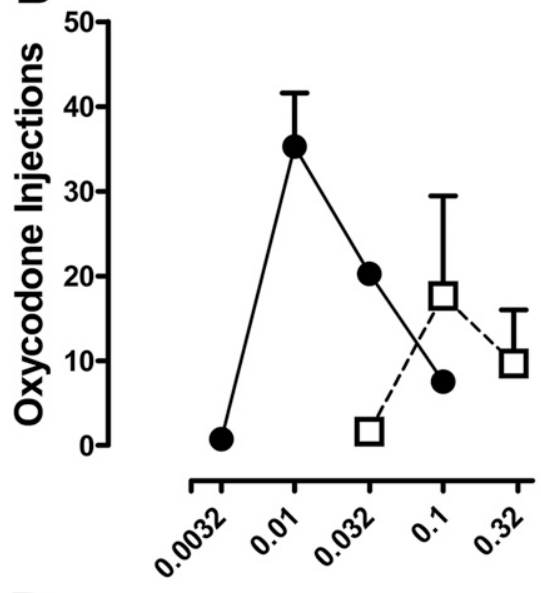

D

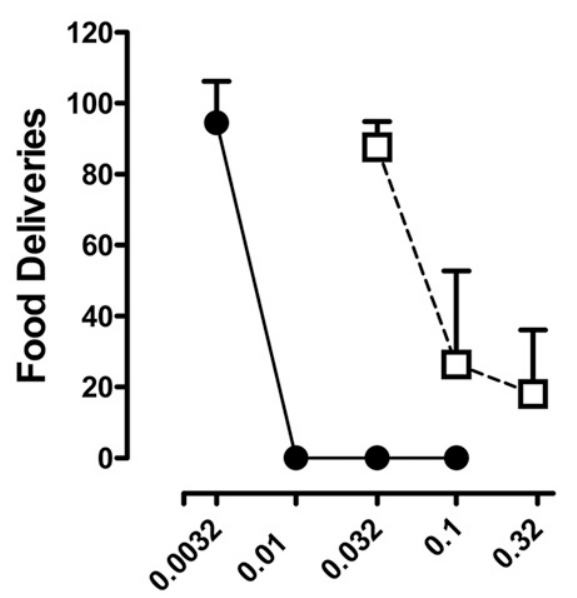

Fig. 1. Effects of chronic buprenorphine treatment on oxycodone self-administration under choice conditions. (A) Percentage injection-lever responding during 90-minute session, before and during treatment with $0.32 \mathrm{mg} / \mathrm{kg}$ per day of chronic buprenorphine. (B) Total number of oxycodone injections selfadministered. (C) Total drug intake (milligrams per kilogram) over 90 minutes. (D) Number of food reinforcers received as a function of oxycodone unit dose available for self-administration. Abscissae: unit dose of oxycodone available for self-administration. Ordinates: percentage injection lever responding (A); number of oxycodone injections (B); total drug intake, milligrams per kilogram $(\mathrm{C})$; and number of food deliveries (D).

\section{Oxycodone (mg/kg/inj)}


$(0.0032 \mathrm{mg} / \mathrm{kg}$ per inj) or higher doses $(0.1 \mathrm{mg} / \mathrm{kg}$ per inj) of oxycodone were available for self-administration, the number of injections was less $(0.8 \pm 0.3$ and $7.5 \pm 1.3$ injections, respectively). Despite the inverted U-shaped dose-response function for number of injections, the total drug intake increased with dose (maximum oxycodone intake over 90 minutes, $0.8 \pm 0.1 \mathrm{mg} / \mathrm{kg}$ at a unit dose of $0.1 \mathrm{mg} / \mathrm{kg}$ per inj, as shown in Fig. 1C, filled symbols). At a unit dose of $0.0032 \mathrm{mg} / \mathrm{kg}$ of oxycodone, subjects allocated almost all responses to the food lever, and at higher doses the subjects responded exclusively on the injection lever, resulting in no food deliveries (Fig. 1D, filled symbols).

Oxycodone Self-Administration During Chronic Buprenorphine Treatment. Chronic treatment with $0.32 \mathrm{mg} / \mathrm{kg}$ per day buprenorphine resulted in an approximately 10-fold rightward shift in the dose-response functions for \% ILR and numbers of injections (Fig. 1, A and B, unfilled symbols). Thus, the peak number of injections occurred when $0.1 \mathrm{mg} / \mathrm{kg}$ per inj of oxycodone was available for selfadministration, and the \% ILR was maximal at doses above $0.032 \mathrm{mg} / \mathrm{kg}$ per inj. Chronic treatment with buprenorphine also resulted in an apparent downward shift in the oxycodone dose-response function, with a maximum of $17.7 \pm 11.8$ oxycodone injections self-administered at a unit dose of $0.1 \mathrm{mg} / \mathrm{kg}$ per inj. As in prechronic dose-response determinations, total drug intake during chronic buprenorphine increased with dose (maximum oxycodone intake over 90 minutes, $3.1 \pm 2.0 \mathrm{mg} / \mathrm{kg}$ at a unit dose of $0.32 \mathrm{mg} / \mathrm{kg}$ per inj, as shown in Fig. 1C, unfilled symbols). At a unit dose of $0.032 \mathrm{mg} / \mathrm{kg}$ of oxycodone during chronic treatment, subjects allocated nearly all responding to the food lever, and at higher unit doses, subjects allocated responding to the injection lever, resulting in fewer food deliveries (Fig. 1D, unfilled symbols).

Reinstatement of Drug-Seeking Behavior Following Priming with Opioid Agonists. Before chronic buprenorphine treatment, a presession priming dose of each of the opioid full agonists reinstated drug-seeking behavior (Fig. 2). The \% ILR increased dose-dependently and was maximal following priming doses of $0.56,0.1$, and $0.32 \mathrm{mg} / \mathrm{kg}$ of methadone, heroin, and oxycodone, respectively. Similarly, the number of saline injections following the priming injection varied as a function of priming dose; the greatest number of saline injections (9 to 10 per 30 -minute session) followed priming doses of $0.32,0.1$, and $0.32 \mathrm{mg} / \mathrm{kg}$ of methadone, heroin, and oxycodone, respectively.

During chronic treatment with $0.1 \mathrm{mg} / \mathrm{kg}$ per day buprenorphine, dose-response functions for all three full agonists shifted rightward for \% ILR, and rightward and downward for number of saline injections (Fig. 2). During chronic treatment with $0.32 \mathrm{mg} / \mathrm{kg}$ per day, the dose-response function for heroin was shifted further rightward for \% ILR but not number of saline injections (Fig. 2B). Following a single priming dose $(1.0 \mathrm{mg} / \mathrm{kg}$ ) of either methadone or oxycodone, the agonist priming effects were unaltered during $0.32 \mathrm{mg} / \mathrm{kg}$ per day compared with $0.1 \mathrm{mg} / \mathrm{kg}$ per day buprenorphine (Fig. 2, A and C). Peak numbers of saline injections were self-administered at doses of $1.0,0.32$, and $1.0 \mathrm{mg} / \mathrm{kg}$ for methadone, heroin, and oxycodone, respectively, during treatment with 0.1 or $0.32 \mathrm{mg} / \mathrm{kg}$ per day buprenorphine. However, the number of saline injections over the 30-minute test period decreased compared with prechronic numbers. Thus, during chronic treatment with $0.1 \mathrm{mg} / \mathrm{kg}$ of buprenorphine, the maximum numbers of saline injections self-administered were $3.0 \pm 2.0$, $5.0 \pm 3.1$, and $4.8 \pm 1.0$ for methadone, heroin, and oxycodone, respectively (see Fig. 2).

The priming strength of opioid partial agonists buprenorphine, butorphanol, and nalbuphine before and during chronic treatment with $0.1 \mathrm{mg} / \mathrm{kg}$ per day buprenorphine is shown in Fig. 3. Before chronic treatment, \% ILR and the number of saline injections increased dose-dependently for all three drugs, with maximal increases following priming doses of $0.01,0.1$, and $0.32 \mathrm{mg} / \mathrm{kg}$ of buprenorphine, butorphanol, and nalbuphine, respectively (Fig. 3). The effects of butorphanol and nalbuphine were relatively consistent among subjects, whereas the effects of buprenorphine varied among individual subjects. On average, priming with buprenorphine elicited only partial reinstatement of drug-seeking behavior (peak $\% \mathrm{ILR}=35.28 \pm 32.36,6.50 \pm 5.75$ injections). During chronic buprenorphine treatment, buprenorphine, butorphanol, and nalbuphine did not reliably reinstate drug-seeking behavior at any of the priming doses tested. These results are evident in the low \% ILR values and the low number of saline injections following all priming doses of the partial agonists (Fig. 3). Thus, prior to daily treatment, a priming dose of $0.01 \mathrm{mg} / \mathrm{kg}$ of buprenorphine resulted in $6.50 \pm 5.75$ injections of saline over the 30-minute test period (Fig. 3A). During chronic treatment, however, none of the buprenorphine priming doses tested, up to $0.032 \mathrm{mg} / \mathrm{kg}$, reinstated any responding on the injection lever. Similarly, the priming dose of $0.1 \mathrm{mg} / \mathrm{kg}$ of butorphanol resulted in the greatest number of saline injections prechronically (8.67 \pm 2.33 injections; Fig. $3 \mathrm{~B})$, whereas priming doses up to $1.8 \mathrm{mg} / \mathrm{kg}$ of butorphanol were unable to reinstate drugseeking behavior during chronic treatment. Finally, a priming dose of $0.32 \mathrm{mg} / \mathrm{kg}$ of nalbuphine resulted in $8.67 \pm 1.45$ saline injections over the 30-minute test period in initial doseresponse determinations (Fig. 3C). However, following chronic treatment, no dose of nalbuphine up to $3.2 \mathrm{mg} / \mathrm{kg}$ reinstated significant levels of drug-seeking behavior.

Opioid-Induced Antinociception and Behavioral Disruption Before and During Chronic Buprenorphine Treatment. Figure 4 shows the dose-response functions for tail withdrawal latency (top panels) and rates of responding (bottom panels) for each of the opioid full agonists before and during chronic buprenorphine treatment. Methadone, heroin, and oxycodone each produced dose-dependent increases in tail withdrawal latency and dose-dependent decreases in rates of responding before chronic buprenorphine treatment. Peak tail withdrawal latencies were produced by doses of 1.0, 0.32, and $0.56 \mathrm{mg} / \mathrm{kg}$ of methadone, heroin, and oxycodone, respectively. These doses of the agonists also produced significant decreases in rates of responding before chronic buprenorphine treatment. During chronic buprenorphine treatment, the dose-response functions for each of the opioid full agonists were shifted rightward, as shown in Fig. 4; the magnitude of shift is represented as changes in $\mathrm{ED}_{50}$ values (Table 1). During chronic treatment with $0.1 \mathrm{mg} / \mathrm{kg}$ per day buprenorphine, doses of $1.8,0.56$, and $1.0 \mathrm{mg} / \mathrm{kg}$ of methadone, heroin, and oxycodone, respectively, were required to produce peak tail withdrawal latencies. These higher doses of the agonists also produced significant decreases in response rates. Doseresponse functions for opioid full agonists were not shifted further rightward during treatment with $0.32 \mathrm{mg} / \mathrm{kg}$ per day buprenorphine, as evident in similar $\mathrm{ED}_{50}$ values (Table 1). As a consequence of changes in the position of the dose-response 
functions, ratios of the $\mathrm{ED}_{50}$ values for the response rate-decreasing and antinociceptive effects of the full agonists were lower during chronic buprenorphine treatment than in initial determinations (Table 1).
Figure 5 shows the dose-response functions for tail withdrawal latency and rates of responding for each of the opioid partial agonists tested before and during chronic buprenorphine treatment. Similar to the higher-efficacy agonists

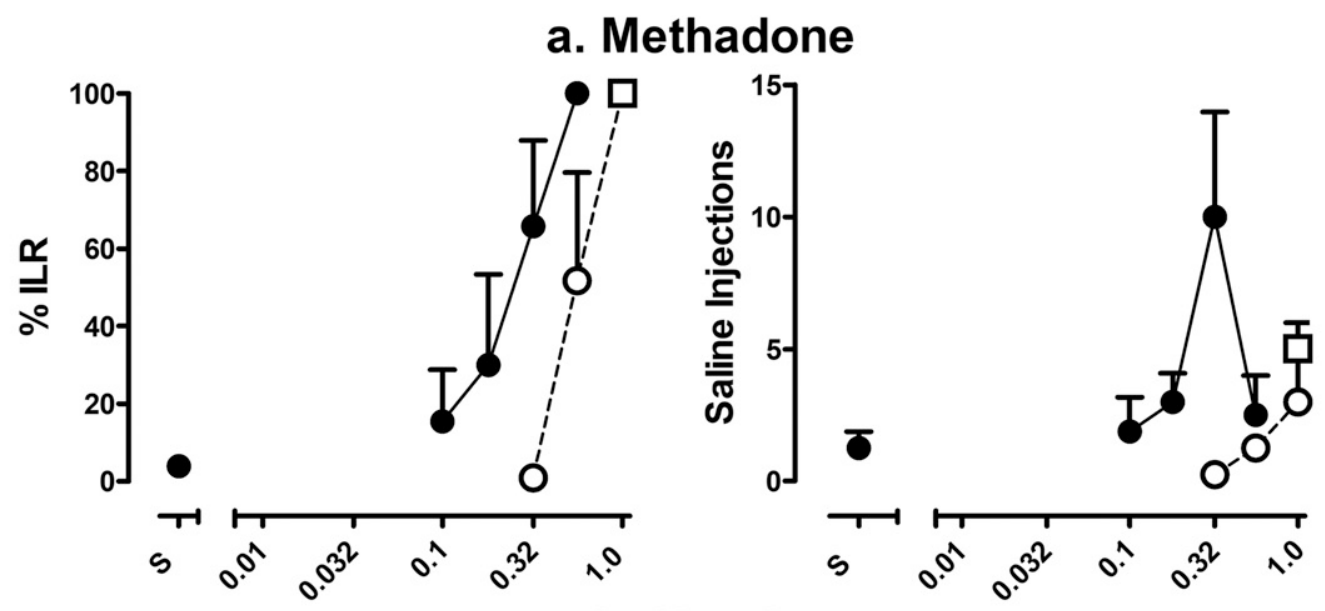

b. Heroin
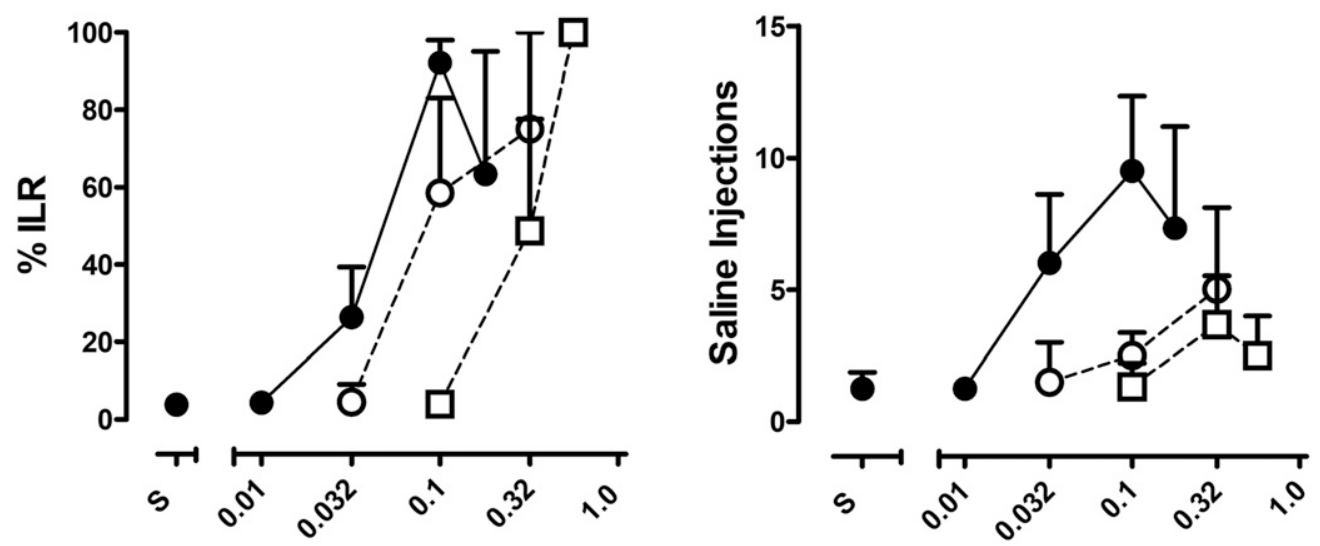

c. Oxycodone
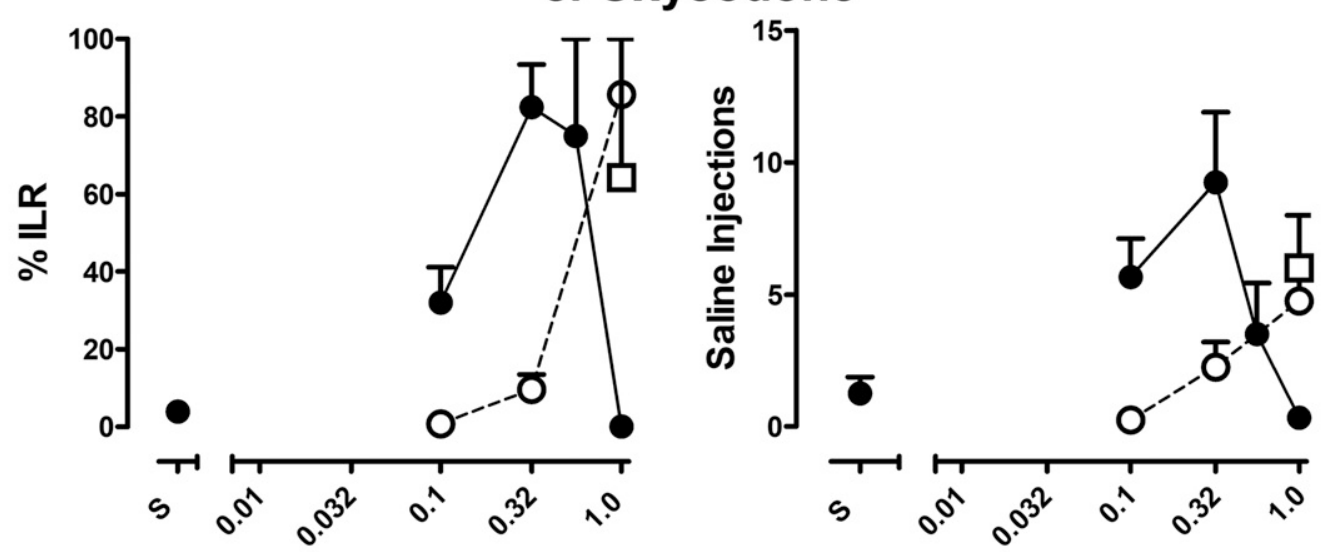

Priming Dose (mg/kg, i.m.)

Pre-chronic

O. Chronic buprenorphine $0.1 \mathrm{mg} / \mathrm{kg}$

Chronic buprenorphine $0.32 \mathrm{mg} / \mathrm{kg}$

Fig. 2. The effects of chronic buprenorphine on the priming strength of opioid full agonists. The ability of methadone (A), heroin (B), and oxycodone (C) to reinstate drug-seeking behavior before and during chronic buprenorphine treatment $(0.1$ and $0.32 \mathrm{mg} / \mathrm{kg}$ per day). Only one dose of oxycodone and methadone was tested during chronic treatment with $0.32 \mathrm{mg} / \mathrm{kg}$ per day. Left panels show the percentage injection lever responding, and right panels show the number of saline injections self-administered over a 30-minute session. Abscissae: dose (milligrams per kilogram) of opioid full agonist as intramuscular priming injection. Ordinate: percentage injection lever responding (left), number of saline injections (right). 


\section{a. Buprenorphine}
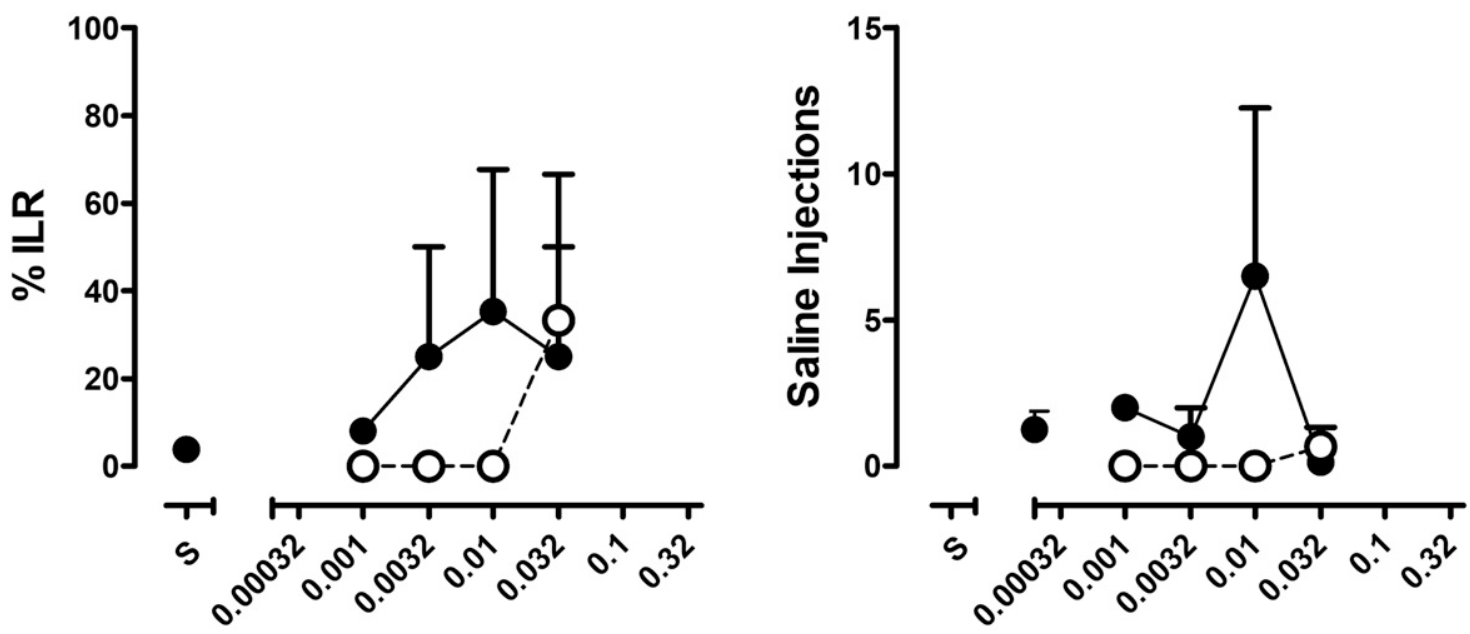

\section{b. Butorphanol}
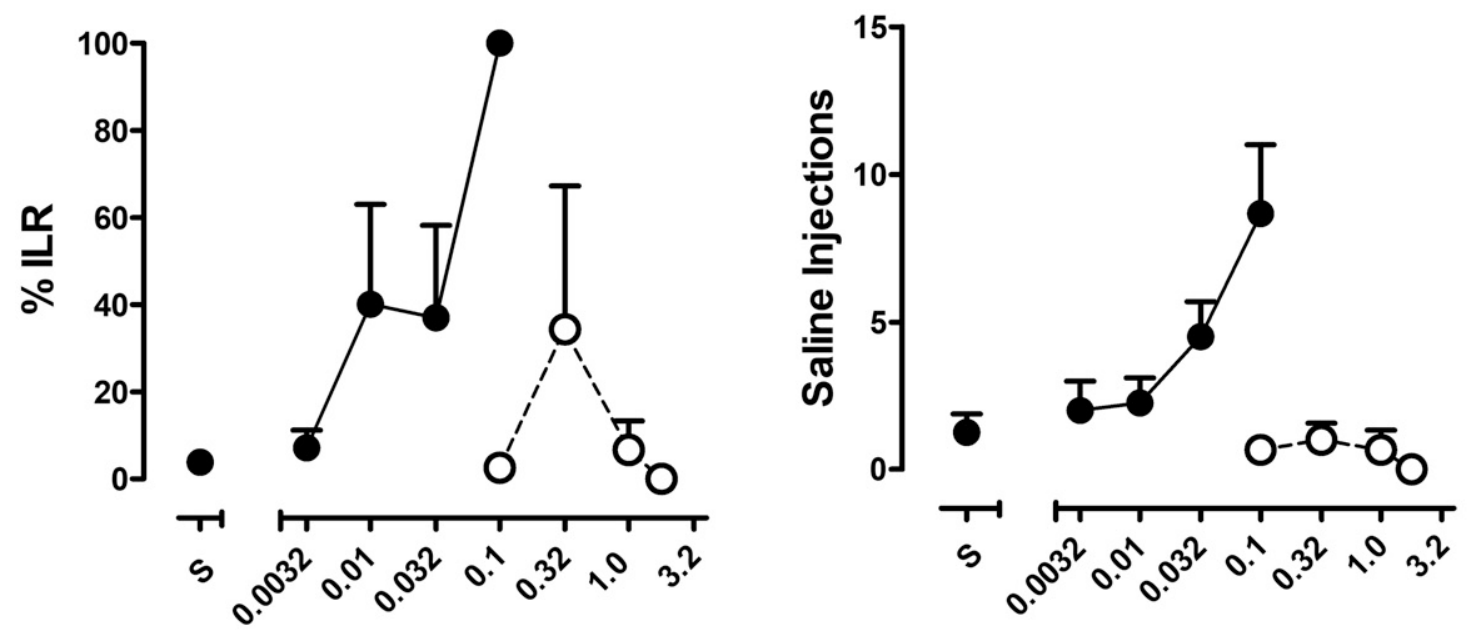

\section{c. Nalbuphine}
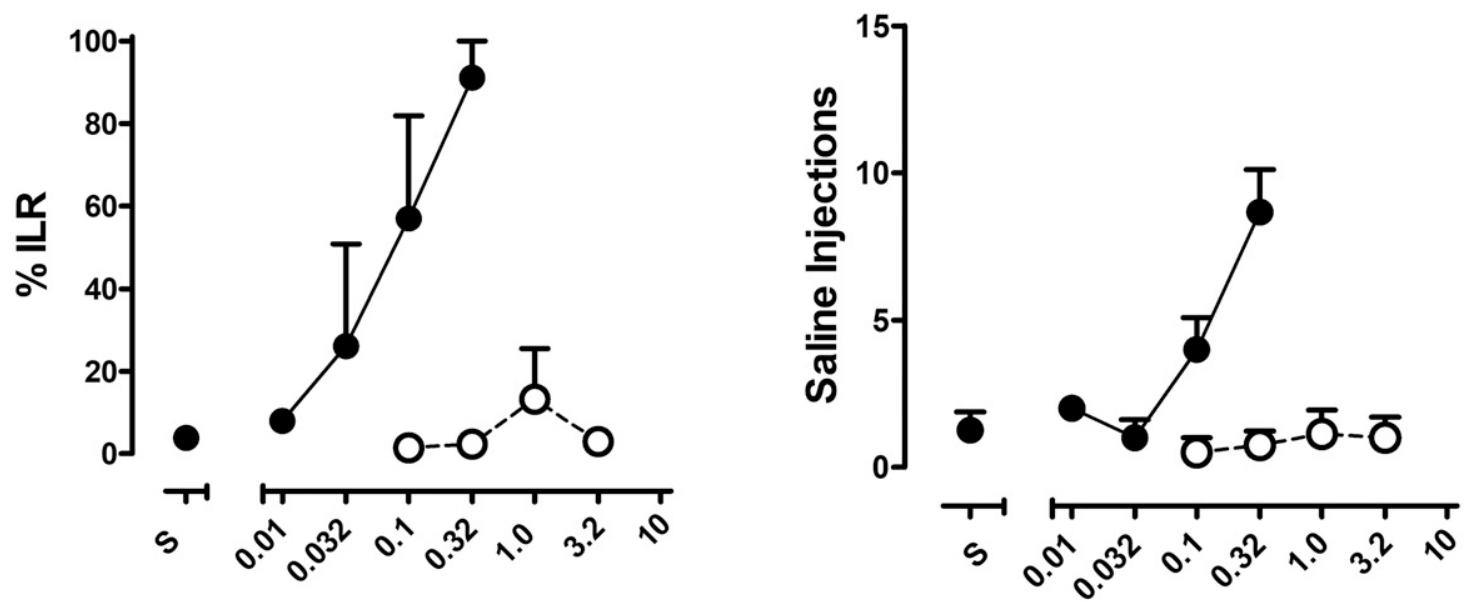

Priming Dose (mg/kg, i.m.)

\section{Pre-chronic O Chronic buprenorphine $0.1 \mathrm{mg} / \mathrm{kg}$}

Fig. 3. The effects of chronic buprenorphine on the priming strength of opioid partial agonists. The ability of buprenorphine (A), butorphanol (B), and nalbuphine (C) to reinstate drug-seeking behavior before and during chronic buprenorphine treatment $(0.1 \mathrm{mg} / \mathrm{kg}$ per day). Left panels show the percentage injection lever responding, and right panels show the number of saline injections self-administered over a 30-minute session. Abscissae: dose (milligrams per kilogram) of opioid partial agonist administered as intramuscular priming injection. Ordinate: percentage injection lever responding (left), number of saline injections (right). 


\section{Pre-chronic $\quad$ o. Chronic buprenorphine $0.1 \mathrm{mg} / \mathrm{kg}$ \\ $\square$ Chronic buprenorphine $0.32 \mathrm{mg} / \mathrm{kg}$}
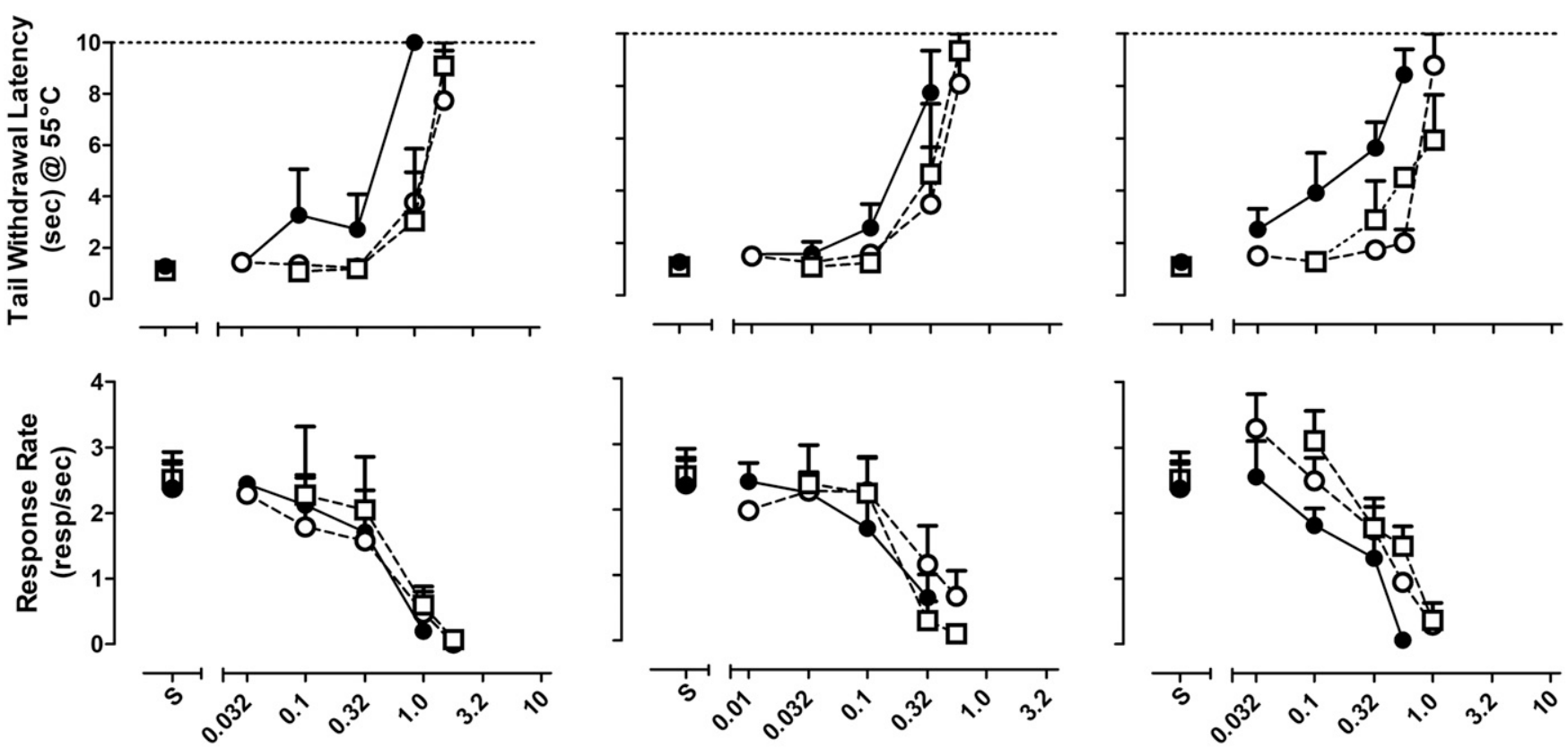

Methadone $(\mathrm{mg} / \mathrm{kg})$

Heroin $(\mathbf{m g} / \mathbf{k g})$

\section{Oxycodone $(\mathrm{mg} / \mathrm{kg})$}

Fig. 4. The effects of chronic buprenorphine on the antinociceptive and behaviorally disruptive effects of opioid full agonists. The ability of methadone, heroin, and oxycodone to produce increases in tail withdrawal latency (top panels) or decreases in food-maintained behavior (bottom panels) before and during chronic buprenorphine treatment ( 0.1 and $0.32 \mathrm{mg} / \mathrm{kg}$ per day). Abscissae: dose (milligrams per kilogram) of opioid full agonist administered using cumulative dosing. Ordinates: latency to withdraw tail from $55^{\circ} \mathrm{C}$ water (seconds) (top panels) and response rate (responses/second) (bottom panels).

described previously, buprenorphine, butorphanol, and nalbuphine initially produced dose-dependent increases in tail withdrawal latency. Buprenorphine and butorphanol, but not nalbuphine, also produced dose-dependent decreases in rates of responding. During chronic treatment with $0.1 \mathrm{mg} / \mathrm{kg}$ per day buprenorphine, the dose-response function for buprenorphine's antinociceptive effects was shifted rightward, as evident in a 6 -fold increase in $\mathrm{ED}_{50}$ value. The dose-response

TABLE 1

$\mathrm{ED}_{50}$ values for each agonist's antinociceptive and behaviorally disruptive effects, and $\mathrm{ED}_{50}$ ratios of antinociceptive effects to response rate disruptive effects

$\mathrm{ED}_{50}$ values given are group means \pm S.E.M. in milligrams per kilogram and were determined from interpolation of individual $(n=3$ or 4$)$ dose-response functions.

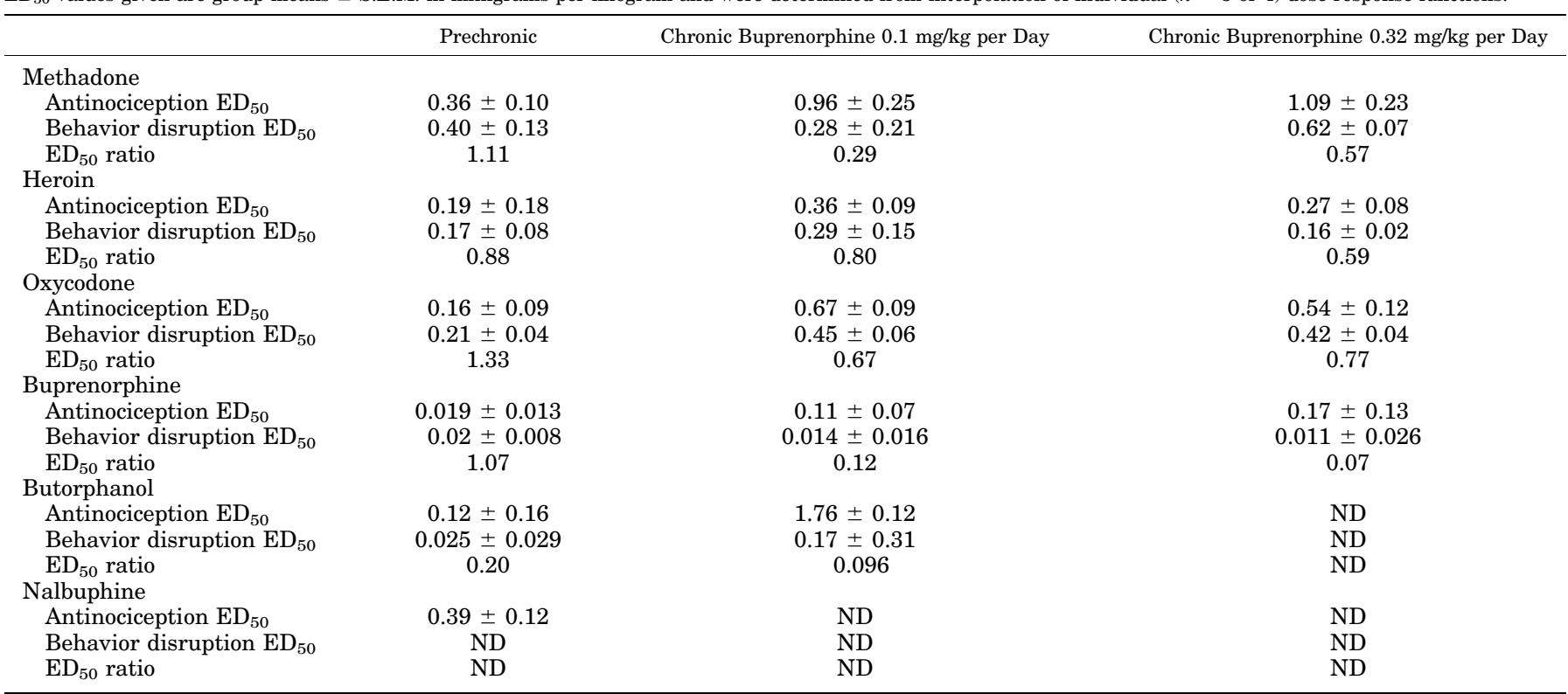




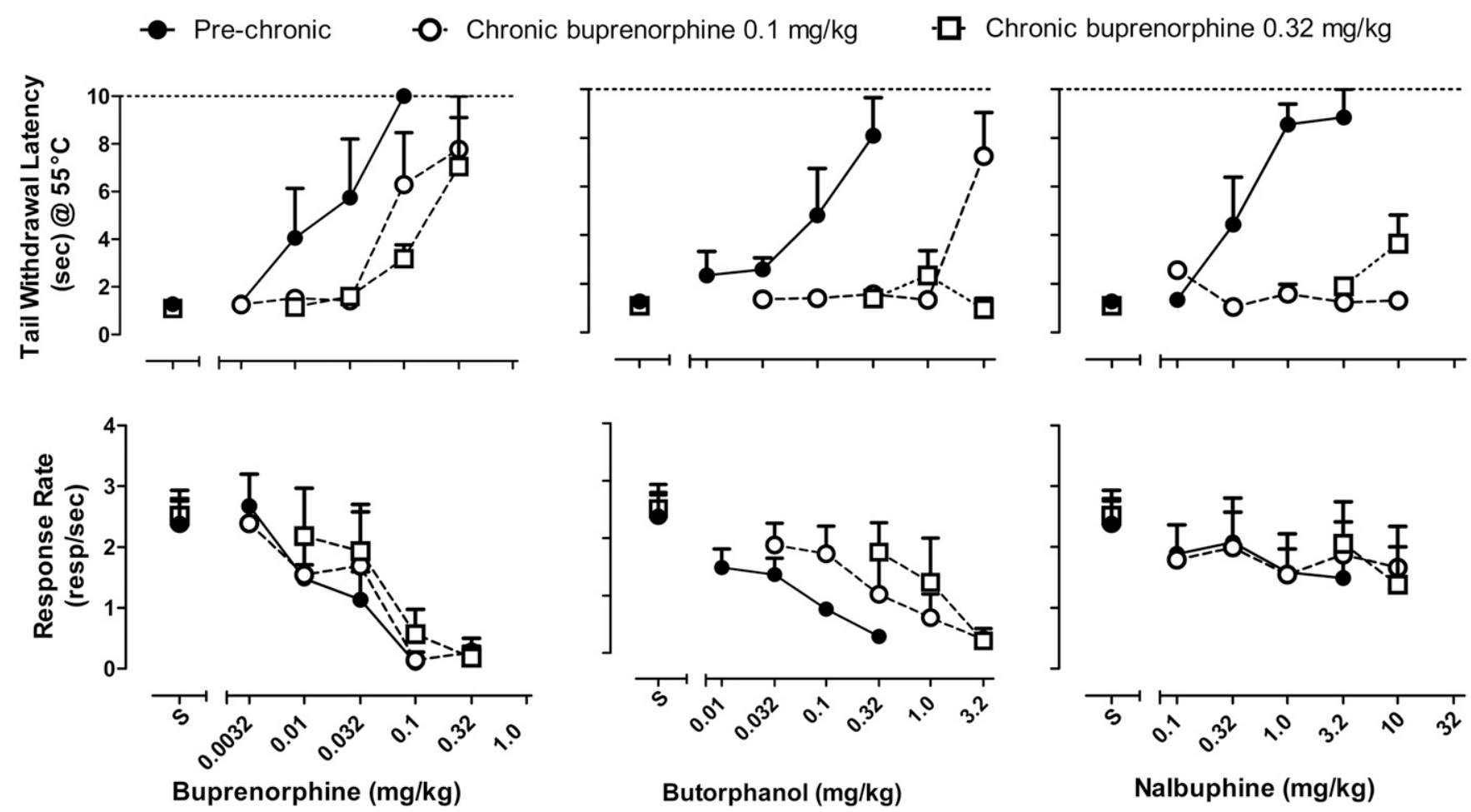

Fig. 5. The effects of chronic buprenorphine on the antinociceptive and behaviorally disruptive effects of opioid partial agonists. The ability of buprenorphine, butorphanol, and nalbuphine to produce increases in tail withdrawal latency (top panels) or decreases in food-maintained behavior (bottom panels) before and during chronic buprenorphine treatment ( 0.1 and $0.32 \mathrm{mg} / \mathrm{kg}$ per day). Abscissae: dose (milligrams per kilogram) of opioid partial agonist administered using cumulative dosing. Ordinates: latency to withdraw tail from $55^{\circ} \mathrm{C}$ water (seconds) (top panels) and response rate (responses/second) (bottom panels).

function for buprenorphine's response rate disruptive effects was also shifted rightward, albeit to a lesser extent. Due to individual variability, these changes in the effects of buprenorphine on responding were not accompanied by significantly increased $\mathrm{ED}_{50}$ values. The differential shifts in dose-response functions for antinociception and response rate disruption yielded a decrease in $\mathrm{ED}_{50}$ ratio during chronic buprenorphine treatment (Table 1).

Butorphanol produced dose-dependent increases in tail withdrawal latency and significant behavioral disruption; thus, decreases in response rates were evident even after cumulative doses that did not significantly increase tail withdrawal latencies $(0.032$ and $0.1 \mathrm{mg} / \mathrm{kg})$. During chronic treatment with $0.1 \mathrm{mg} / \mathrm{kg}$ per day buprenorphine, the doseresponse function for butorphanol's antinociceptive effects was shifted rightward 15-fold; an increase in buprenorphine dosage to $0.32 \mathrm{mg} / \mathrm{kg}$ per day did not lead to increases in the effects of butorphanol on tail withdrawal latencies. The doseresponse functions for butorphanol's response rate-disrupting effects were also shifted rightward during buprenorphine treatment, yielding an increase in $\mathrm{ED}_{50}$ value and, during the daily regimen of $0.1 \mathrm{mg} / \mathrm{kg}$ per day buprenorphine, a decrease in $\mathrm{ED}_{50}$ ratio. $\mathrm{ED}_{50}$ values could not be calculated during $0.32 \mathrm{mg} / \mathrm{kg}$ per day buprenorphine due to the nature of the change in position of the butorphanol dose-response function.

Nalbuphine produced dose-dependent increases in tail withdrawal latency but did not significantly alter rates of responding, even after the highest dose $(3.2 \mathrm{mg} / \mathrm{kg})$. During chronic buprenorphine treatment, nalbuphine did not produce significant increases in tail withdrawal latency or decreases in response rates up to a dose of $10 \mathrm{mg} / \mathrm{kg}$, precluding the calculation of $\mathrm{ED}_{50}$ values.

\section{Discussion}

In agreement with previous studies in other species, oxycodone produced reinforcing effects in squirrel monkeys, evident in its ability to maintain self-administration behavior under concurrent schedules of intravenous drug and food reinforcement (Beardsley et al., 2004; Altschuler et al., 2015). Thus, the availability of saline or low unit doses of oxycodone led to responding that was nearly exclusively allocated to the food lever, whereas the availability of higher unit doses of oxycodone led to dose-dependent increases in the allocation of responding to the injection lever. High unit doses which would be expected to decrease overall response rates continued to maintain responding nearly exclusively on the injection lever, yielding a monotonic dose-response function and illustrating the utility of the present procedures for evaluating relative reinforcing strength.

Following chronic buprenorphine treatment, the potency of oxycodone's reinforcing effects was reduced, as evident in a rightward shift in the dose-response function for its selfadministration. Acute and chronic treatment with buprenorphine previously has been shown to produce rightward and/or downward shifts in dose-response functions for opioid selfadministration (Mello et al., 1983; Winger et al., 1992; Winger and Woods, 1996; Mello and Negus, 1998). In conjunction with those findings, the present data suggest that buprenorphine, 
as a replacement therapy, may reduce opioid self-administration by attenuating the reinforcing strength of other opioids. Although the precise mechanism by which buprenorphine shifted the oxycodone dose-response function rightward is uncertain, it is likely that, in addition to buprenorphine's partial antagonist effects, tolerance to its agonist effects also was involved (see below).

As demonstrated here and in previous studies using choice procedures to assess reinstatement (Gasior et al., 2004), priming effects of the opioids were produced by pretreatment with doses that led to the allocation of high levels of responding to the food lever, whereas higher, behaviorally disruptive doses of opioids decreased responding on both the injection and food levers. Interestingly, unlike the other five agonists tested, buprenorphine did not induce 100\% ILR either before or during chronic treatment. Although higher doses were tested that significantly reduced responding in all animals, the large S.E. in the \% ILR of buprenorphine reinstatement suggests the priming strength of buprenorphine is highly variable.

Previous studies have shown that buprenorphine reduces opioid self-administration in rats (Chen et al., 2006), monkeys (Mello and Negus, 1998), and humans (Comer et al., 2001). Yet, the ability of chronic buprenorphine to attenuate the priming strength of opioids has not been investigated previously. In the present studies, the dose-response functions for the priming strength of opioid full agonists were shifted rightward 2-, 10-, and 3-fold for methadone, heroin, and oxycodone, respectively, during chronic treatment with buprenorphine. However, each full agonist was still able to reinstate drug-seeking behavior, albeit at a higher dose. In contrast, none of the partial agonists reliably reinstated drug-seeking behavior during chronic treatment with $0.1 \mathrm{mg} / \mathrm{kg}$ per day buprenorphine. These dramatic differences in the priming strength of opioid full and partial agonists during chronic treatment suggest that the ability of buprenorphine to protect against drug-seeking instigated by opioid agonists can depend on their efficacy and, likely, related differences in receptor reserve. Moreover, these data indicate that, in addition to partial antagonism by buprenorphine, tolerance to agonist actions also contributed to the observed rightward shifts in priming dose-response functions.

The antinociceptive and behaviorally disruptive effects of opioid agonists have been studied previously using the procedure described in the current studies (Withey et al., 2018) and were confirmed in initial dose-response determinations. As with priming strength, the effects of buprenorphine treatment on the antinociceptive effects of the tested opioids differed qualitatively depending on their efficacy. Thus, the antinociceptive efficacies of methadone, heroin, and oxycodone were maintained during chronic treatment with buprenorphine, albeit with decreased potency, and only small rightward shifts were evident in their dose-response functions. Even though the rightward shift is modest for full agonist dose-response functions, the magnitude of shift negatively correlates with the efficacy of the opioid agonist tested (i.e., methadone $=$ heroin $<$ oxycodone $<$ buprenorphine $<$ butorphanol $<$ nalbuphine). Therefore, it may be concluded, at least tentatively, that buprenorphine alters the antinociceptive strength of opioid drugs as a function of $\mu$-agonist efficacy. This suggests that opioid full agonists may still offer pain relief in buprenorphine-maintained individuals, albeit at somewhat higher effective doses. On the other hand, depending on their efficacy, partial agonists may become much less effective or even ineffective during buprenorphine treatment.

The efficacy-related changes in the effects of opioids on priming strength and antinociception during chronic buprenorphine treatment were less evident in their effects on rates of operant responding. Thus, dose-response functions for the response rate-decreasing effects of methadone, heroin, and oxycodone were not significantly shifted rightward during treatment with chronic buprenorphine. The differences in magnitude of shift for both antinociception and operant responding are reflected in $\mathrm{ED}_{50}$ ratios (i.e., potency ratio of antinociceptive to behaviorally disruptive effects). Thus, the dose-response functions for antinociception were shifted further rightward than the dose-response functions for response rate disruption, resulting in decreased $\mathrm{ED}_{50}$ ratios during chronic buprenorphine treatment of all drugs (Table 1). However, the magnitude of this decrease varied across agonists. For example, $\mathrm{ED}_{50}$ ratios for the full agonists methadone and oxycodone during chronic buprenorphine treatment were approximately 2-fold lower than before chronic treatment, whereas the $\mathrm{ED}_{50}$ ratios for acute buprenorphine were 15-fold lower during chronic treatment, and $\mathrm{ED}_{50}$ ratios for butorphanol could not be calculated during treatment with $0.32 \mathrm{mg} / \mathrm{kg}$ per day buprenorphine. The reason for the difference in the extent to which buprenorphine treatment modified antinociception and operant behavior is unclear. Of interest, buprenorphine itself induces potent and reliable response rate-decreasing effects in squirrel monkeys that, based upon $\mathrm{p} A_{2}$ analysis, appear to reflect its $\mu$-receptormediated actions (Withey et al., 2018). However, as with the higher-efficacy agonists, the dose-response function for buprenorphine's rate-decreasing effects was not shifted significantly rightward. In view of the tolerance to the effects of buprenorphine in reinstatement and tail withdrawal studies, these data suggest that its rate-decreasing effects in squirrel monkeys may command a larger receptor reserve than its priming and antinociceptive effects.

The opioids nalbuphine and butorphanol are characterized as partial $\mu$-/partial $\kappa$-receptor agonists. As reported previously, nalbuphine did not induce response rate-decreasing effects either prechronically or during chronic buprenorphine treatment (Withey et al., 2018). These data are in keeping with the relatively low efficacy of nalbuphine that has been reported previously (Walker and Young, 1993) and that was evident in the present reinstatement and tail withdrawal studies. In contrast, butorphanol induced significant response rate-decreasing effects that were antagonized during chronic buprenorphine treatment. This may reflect tolerance to or antagonism of the $\mu$-mediated actions of butorphanol but also may include antagonism of its $\kappa$-mediated actions by buprenorphine (Negus and Dykstra, 1988; Picker et al., 1990).

\section{Acknowledgments}

The authors thank Sarah Leinwand and Lyndsey Wood for their outstanding technical assistance in conducting experiments.

\author{
Authorship Contributions \\ Participated in research design: Withey, Spealman, Bergman, \\ Paronis. \\ Conducted experiments: Withey. \\ Performed data analysis: Withey.
}


Wrote or contributed to the writing of the manuscript: Withey, Spealman, Bergman, Paronis.

\section{References}

Altschuler JH, Niikura KBE, Kreek MJ, and Zhang Y (2015) Adolescent oxycodone self-administration alters subsequent antinociceptive effect of oxycodone in C57BL/6J mice in adulthood. Drug Alcohol Depend 156:E6.

Beardsley PM, Aceto MD, Cook CD, Bowman ER, Newman JL, and Harris LS (2004) Discriminative stimulus, reinforcing, physical dependence, and antinociceptive effects of oxycodone in mice, rats, and rhesus monkeys. Exp Clin Psychopharmacol 12:163-172.

Bergman $J$ and Paronis CA (2006) Measuring the reinforcing strength of abused drugs. Mol Interv 6:273-283.

Bickel WK, Stitzer ML, Bigelow GE, Liebson IA, Jasinski DR, and Johnson RE (1988) Buprenorphine: dose-related blockade of opioid challenge effects in opioid dependent humans. J Pharmacol Exp Ther 247:47-53.

Briscoe RJ, Winger G, Lewis JW, and Woods JH (2000) Methoclocinnamox: time course of changes in alfentanil-reinforced responding in rhesus monkeys. Psychopharmacology (Berl) 148:393-399.

Chen SA, O'Dell LE, Hoefer ME, Greenwell TN, Zorrilla EP, and Koob GF (2006) Unlimited Access to Heroin Self-Administration: Independent Motivational Markers of Opiate Dependence. Neuropsychopharmacology 31:2692-2707 In this issue.

Comer SD, Collins ED, and Fischman MW (2001) Buprenorphine sublingual tablets: effects on IV heroin self-administration by humans. Psychopharmacology (Berl) 154:28-37.

Dykstra LA and Woods JH (1986) A tail withdrawal procedure for assessing analgesic activity in rhesus monkeys. J Pharmacol Methods 15:263-269.

Gasior M, Paronis CA, and Bergman J (2004) Modification by dopaminergic drugs of choice behavior under concurrent schedules of intravenous saline and food delivery in monkeys. J Pharmacol Exp Ther 308:249-259.

Goldberg SR (1973) Comparable behavior maintained under fixed-ratio and secondorder schedules of food presentation, cocaine injection or d-amphetamine injection in the squirrel monkey. $J$ Pharmacol Exp Ther 186:18-30.

Huang P, Kehner GB, Cowan A, and Liu-Chen LY (2001) Comparison of pharmacological activities of buprenorphine and norbuprenorphine: norbuprenorphine is a potent opioid agonist. J Pharmacol Exp Ther 297:688-695.

Jones JD, Sullivan MA, Vosburg SK, Manubay JM, Mogali S, Metz V, and Comer SD (2015) Abuse potential of intranasal buprenorphine versus buprenorphine/ naloxone in buprenorphine-maintained heroin users. Addiction Biology 20 (4): 784-798 In this issue.

Kishioka S, Paronis CA, Lewis JW, and Woods JH (2000) Buprenorphine and methoclocinnamox: agonist and antagonist effects on respiratory function in rhesus monkeys. Eur J Pharmacol 391:289-297.

Liguori A, Morse WH, and Bergman J (1996) Respiratory effects of opioid full and partial agonists in rhesus monkeys. J Pharmacol Exp Ther 277: $462-472$.

Mello NK, Bree MP, and Mendelson JH (1983) Comparison of buprenorphine and methadone effects on opiate self-administration in primates. J Pharmacol Exp Ther 225:378-386.

Mello NK and Mendelson JH (1980) Buprenorphine suppresses heroin use by heroin addicts. Science 207:657-659.

Mello NK and Negus SS (1998) The effects of buprenorphine on self-administration of cocaine and heroin "speedball" combinations and heroin alone by rhesus monkeys. J Pharmacol Exp Ther 285:444-456.
Negus SS, Bidlack JM, Mello NK, Furness MS, Rice KC, and Brandt MR (2002) Delta opioid antagonist effects of buprenorphine in rhesus monkeys. Behav Pharmacol 13:557-570.

Negus SS and Dykstra LA (1988) Kappa antagonist properties of buprenorphine in the shock titration procedure. Eur J Pharmacol 156:77-86.

Nielsen S, Hillhouse M, Mooney L, Fahey J, and Ling W (2012) Comparing buprenorphine induction experience with heroin and prescription opioid users. $J$ Subst Abuse Treat 43:285-290.

Nielsen S and Taylor DA (2005) The effect of buprenorphine and benzodiazepines on respiration in the rat. Drug Alcohol Depend 79:95-101.

Paronis CA and Bergman J (2011) Buprenorphine and opioid antagonism, tolerance, and naltrexone-precipitated withdrawal. J Pharmacol Exp Ther 336:488-495.

Paronis CA, Gasior M, and Bergman J (2002) Effects of cocaine under concurrent fixed ratio schedules of food and IV drug availability: a novel choice procedure in monkeys. Psychopharmacology (Berl) 163:283-291.

Picker MJ, Negus SS, and Craft RM (1990) Butorphanol's efficacy at mu and kappa opioid receptors: inferences based on the schedule-controlled behavior of nontolerant and morphine-tolerant rats and on the responding of rats under a drug discrimination procedure. Pharmacol Biochem Behav 36:563-568.

Rance MJ (1979) Animal and molecular pharmacology of mixed agonist-antagonist analgesic drugs. Br J Clin Pharmacol 7 (Suppl 3):281S-286S.

Romero DV, Partilla JS, Zheng QX, Heyliger SO, Ni Q, Rice KC, Lai J, and Rothman RB (1999) Opioid peptide receptor studies. 12. Buprenorphine is a potent and selective mu/kappa antagonist in the [35S]-GTP-gamma-S functional binding assay. Synapse 34:83-94.

Rosenthal RN, Lofwall MR, Kim S, Chen M, Beebe KL, and Vocci FL (2016) Effect of Buprenorphine Implants on Illicit Opioid Use Among Abstinent Adults With Opioid Dependence Treated With Sublingual Buprenorphine: A Randomized Clinical Trial. JAMA 316 (3):282-290 In this issue.

Silverman SM (2009) Opioid induced hyperalgesia: clinical implications for the pain practitioner. Pain Physician 12:679-684.

Tkacz J, Severt J, Cacciola J, and Ruetsch C (2012) Compliance with buprenorphine medication-assisted treatment and relapse to opioid use. Am J Addict 21:55-62.

Walker EA and Young AM (1993) Discriminative-stimulus effects of the low efficacy mu agonist nalbuphine. J Pharmacol Exp Ther 267:322-330.

Walker EA, Zernig G, and Woods JH (1995) Buprenorphine antagonism of mu opioids in the rhesus monkey tail-withdrawal procedure. J Pharmacol Exp Ther 273:1345-1352.

Walsh SL, Comer SD, Lofwall MR, Vince B, Levy-Cooperman N, Kelsh D, Coe MA, Jones JD, Nuzzo PA, Tiberg F, et al. (2017) Effect of buprenorphine weekly depot (CAM2038) and hydromorphone blockade in individuals with opioid use disorder: a randomized clinical trial. JAMA Psychiatry 74:894-902.

Walsh SL, Preston KL, Bigelow GE, and Stitzer ML (1995) Acute administration of buprenorphine in humans: partial agonist and blockade effects. J Pharmacol Exp Ther 274:361-372.

Winger G and Woods JH (1996) Effects of buprenorphine on behaviour maintained by heroin and alfentanil in rhesus monkeys. Behav Pharmacol 7:155-159.

Winger G, Skjoldager P, and Woods JH (1992) Effects of buprenorphine and other opioid agonists and antagonists on alfentanil- and cocaine-reinforced responding in rhesus monkeys. J Pharmacol Exp Ther 261:311-317.

Withey SL, Paronis CA, and Bergman J (2018) Concurrent assessment of the antinociceptive and behaviorally disruptive effects of opioids in squirrel monkeys. $J$ Pain 19:728-740.

Address correspondence to: Carol A. Paronis, McLean Hospital, 115 Mill Street, Belmont, MA 02478. E-mail: cparonis@mclean.harvard.edu 